\title{
THE
}

\section{Seeing, Believing and Learning to be Skeptical: Supporting Language Learning through Advertising Analysis Activities}

\author{
Renee Hobbs \\ University of Rhode Island, hobbs@uri.edu \\ Haixia $\mathrm{He}$ \\ Michael Robbgrieco
}

Follow this and additional works at: https://digitalcommons.uri.edu/com_facpubs

The University of Rhode Island Faculty have made this article openly available.
Please let us know how Open Access to this research benefits you.

This is a pre-publication author manuscript of the final, published article.

Terms of Use

This article is made available under the terms and conditions applicable towards Open Access Policy Articles, as set forth in our Terms of Use.

\section{Citation/Publisher Attribution}

Hobbs, Renee, et al. "Seeing, Believing, and Learning to Be Skeptical: Supporting Language Learning Through Advertising Analysis Activities." TESOL Journal, vol. 6, 2014, pp. 447-475. http://dx.doi.org/ 10.1002/tesj.153.

Available at: http://dx.doi.org/10.1002/tesj.153 
Running head: SEEING, BELIEVING, SKEPTICAL

\author{
Abstract \\ Seeing, Believing and Learning to be Skeptical: \\ Supporting Language Learning through Advertising Analysis Activities
}

This study documents how an ESL high school teacher working with new immigrants ages 14 20 supported the development of their critical thinking and English language skills by using advertising analysis activities. This paper examines the use of key critical questions for analyzing media messages and documents a variety of instructional activities designed to strengthen students' vocabulary, reading, and discussion skills to build inferential thinking, and critical analysis skills. In this paper, we focus on four instructional practices used by the participating teacher, which all rely on strategies for applying critical questions to analyze advertising: (1) the cloze technique; (2) the question generation ("Jeopardy!") approach, (3) practice in analyzing ads using critical questions in class discussion, and (4) a collaborative online writing activity resulting in the creation of a multi-paragraph multimedia document. By focusing on print, or magazine ads, the teacher was able to exploit the rich visual communication, limited use of words, and relative simplicity of elements as a means to promote language production, reception and comprehension. These activities provided a meaningful opportunity for students to practice their speaking, listening, reading and writing skills in English while supporting the development of abstract thinking, balancing the learning of new academic language and cultural knowledge and connecting with students' prior knowledge, home cultures and everyday experience.

Key Words: language, learning, advertising, analysis, critical thinking, media literacy, technology, new immigrant, adolescents, English, vocabulary, online writing, language, listening, speaking, ESL 
Seeing, Believing and Learning to be Skeptical:

Supporting Language Learning through Advertising Analysis Activities

Learning a language is a dynamic social activity: through interacting with others about the symbolic environment in both classrooms and informal spaces, learners gain knowledge through observation, practice and experience. ESL teachers have long used a variety of materials as resources for supporting learners' understanding of language and culture: books, magazines, TV shows, news programs, films, graphic novels, comics, web pages, online fiction, e-books, reality programs and advertising (Vize, 2011). But apart from the informative value of such resources, in language arts classrooms in the United States, the United Kingdom, Canada, Australia and other countries, media texts are sometimes used as objects of study themselves (Hobbs \& Jensen, 2009). For example, the genre of advertising may be explored to address the rhetorical function of persuasion; TV news may be studied to examine rhetorical concepts of tone, target audience and point of view. For educators who are teaching English to non-native speakers, the use of popular culture materials, including print and moving image media, may support language learning skills while also improving critical thinking.

Constructivist learning theory, as articulated by scholars including John Dewey (1933) and Lev Vygotsky (1978; Wertsch,1985), has shaped educators' awareness of the importance of building connections between the classroom and their students' cultures. Critical thinking skills, including reflection, inference, and synthesizing information, enable people to make reasoned judgments that connect the classroom to everyday life. Critical social theorists emphasize how social activities reflect and shape human relationships, ways of knowing and even the material 
conditions of society (Habermas, 1998). Language is at the heart of how personal and social identities are constructed. By engaging in activities within a community of practice, learners participate in specific social activities that help support their intellectual, social, emotional and linguistic competencies. In sociocultural approaches, language learning occurs socially as members of communities share knowledge and understandings shaped by cultural and historical contexts, rather than through direct instruction and memorization. In a review of L2 learning over the past 40 years, Johnson (2006, p. 237) explains that scholars gradually began to focus on the individual within the context of the cultural environment, recognizing that ordinary "social activities are regulated by normative ways of reasoning." Teaching critical thinking about advertising, mass media and popular culture is generative - that is, a form of inquiry that produces conversations with wide-ranging variations in message interpretation, creating opportunities for awareness and consciousness raising (Freire, 1973). But Pennycook's (1999, p. 336) review of critical approaches to TESOL notes an essential tension between liberal progressive educators who may aim to "make people aware of their own oppression" and others who may see this work as too transmission-oriented and essentially patronizing. For these reasons, it is important to examine the instructional practices used in exploring advertising in ways that meet the unique needs of L2 learners.

This paper examines the use of key critical questions for analyzing media messages and documents a variety of instructional activities designed to strengthen students' vocabulary, reading, and discussion skills to build inferential thinking, and critical analysis skills. In this paper, we focus on four instructional practices used by the participating teacher, which all rely on strategies for applying critical questions to analyze advertising: (1) the cloze technique; (2) the question generation (“Jeopardy!”) approach, (3) practice in analyzing ads using critical 
questions in class discussion, and (4) a collaborative online writing activity resulting in the creation of a multi-paragraph multimedia document. By focusing on print, or magazine ads, the teacher was able to exploit the rich visual communication, limited use of words, and relative simplicity of elements as a means to promote language production, reception and comprehension. By exploring the work of one high school TESOL teacher teaching who taught new immigrant beginner ELLs in an urban public high school, we examine the instructional practices used to scaffold the development of students' media analysis skills. First, we briefly review the literature on advertising and media literacy education in K-12 and ELL classrooms.

\section{Advertising and Media Literacy in the ESL Classroom}

The use of film and media in the classroom has become an accepted method for teaching and learning (Bremer, 2011). Many ESL and EFL educators rely on newspapers, magazines, advertisements, Internet sites, film, and TV as convenient, up-to-date sources of authentic communication. Quinlisk (2003) frames media literacy as a way to pull back the curtain on media's power in shaping reality, describing her own work with L2 learners in analyzing advertising, news and issues of representation. For example, she describes one activity where learners developed a research project looking at the role of women as portrayed in TV dramas, advertisements, and movies. More recently, Park (2009) used articles from the New Yorker with English language learners in South Korea to promote critical reading, using controversial reading selections about contemporary social issues, activating students' prior knowledge and opinions in a pre-reading activity, followed by discussion questions designed to help students identify the reliability of data sources and the propaganda or bias found in the article. After a rich discussion, student papers demonstrated that learners gained the ability to develop claims based on the ideas 
from the reading and discussion. They made active use of modal verbs (e.g., may, might, can), conditionals (e.g., if, that) and epistemic phrases (e.g., in my opinion, I suppose), which indicate an appreciation of the constructed nature of knowledge. The author notes that while students did not discuss political issues that led to social action, inquiry was promoted and students led discussions, which built their confidence and self-esteem.

Advertising is everywhere: on TV and radio, in newspapers and magazines, on the Internet and social media, and at the bus station, subway, airport and in many other public places. All age groups are affected by advertising, both because different persuasive processes operate at different ages, and, at each phase of life, people are targeted by age-specific forms of advertising (Livingstone \& Helsper, 2004). Advertising has been a topic of study in high school since the early 1930s, when journalists and educators recognized the need to introduce the concepts of propaganda and public opinion. In the 1930s, a new generation of writers, activists and scholars in literary analysis, linguistics and education began to recognize the power of language to shape reality. Alfred Korzybski’s Science and Sanity, first published in 1933, presented a nonAristotelian philosophy that emphasized the need for heightened awareness of the power of symbols on human consciousness and social action. During WWII, when the field of communication studies was in its infancy, the study of propaganda emerged with the Institute for Propaganda Analysis in 1937. Members of this group developed the now-famous seven techniques of propaganda: name-calling, glittering generalities, transfer, testimonial, plain-folks, card-stacking, and bandwagon. Clyde Miller, a journalist/author received funding from department store magnate Edward Filene to promote curriculum materials for the identification of propaganda techniques, and it is estimated that over one million students used these materials within the first three years of its creation. As the popularity of these concepts grew, the Institute 
of Propaganda Analysis acknowledged that simple detection of propaganda was not enough in the struggle to maintain democracy in an era of mass persuasion. Americans continually need to evaluate whether a particular form of propaganda is directed to a socially useful end or a socially damaging one (Hayakawa, 1939).

By the 1950s, the rise of television in American culture led to concern among parents, teachers and citizens about its influence on children and youth. Politicians and thought leaders had conflicting views about how new forms of advertising and entertainment were changing family leisure time, the consumption of goods and services, and the political campaign process. In the 1970s, concerns about unfair and deceptive advertising to children led to Congressional hearings about the potentially harmful influence of advertising. Over the past sixty years, concern about media's influence on social values and behavior has shaped the tenor of American cultural life. While media literacy is sometimes seen as an inoculation against propaganda and other negative media influences and as a means to resist and challenge media power (Kellner \& Share, 2009), it is also conceptualized as a metacognitive strategy to increase one's individual and social empowerment (Hobbs, 2010).

Typical classroom activities in media literacy include a blend of accessing, analyzing, evaluating and creating messages in a wide variety of forms (Auferderheide, 1993). In recent years, media literacy education has gained some momentum in the United States because of the increased emphasis on digital and new literacies, which now incorporates media and information literacy, collaboration and problem-solving skills, and stress on the social responsibilities of communication. In 2009, the National Association for Media Literacy Education (NAMLE) developed an influential policy document, the Core Principles of Media Literacy Education in the United States. It states, "The purpose of media literacy education is to help individuals of all 
ages develop the habits of inquiry and skills of expression that they need to be critical thinkers, effective communicators and active citizens in today's world." (NAMLE, 2009, p. 1). Informed by long-standing curricula in Canada, England, and Australia, U.S. educators at the 1993 Media Literacy National Leadership Conference agreed upon the following concepts that should be included in the analysis of media messages: (a) media messages are constructed; (b) media messages are produced within economic, social, political, historical and aesthetic contexts; (c) the interpretative meaning-making processes involved in message reception consists of an interaction between the reader, the text and the culture; (d) media have unique 'languages,' characteristics which typify various forms, genres and symbol systems of communication; and (e) media representations play a role in people's understanding of social reality (Hobbs, 2007). Typically, U.S. media literacy education includes a focus on news, advertising, entertainment, issues of representation and media ownership (Hobbs, 2010).

Learning to analyze ads may help consumers distinguish between rational and emotional appeals, enhancing people's ability to make reasonable choices about products. Some scholars and educators have argued that by learning to critically analyze advertising, people may become resistant to its allure. Researchers believe that this may discourage materialistic values, promote critical thinking and support communication skills (Brucks, Goldberg, \& Armstrong, 1986). In a comprehensive review of the literature on children, adolescents and advertising, Young (1990) argues that (1) knowledge about persuasive tactics along with (2) an understanding of the purpose and function of a media message are key components needed to acquire critical thinking skills about advertising. During the 1970s, the concept of media literacy was first formulated as a type of "cognitive defense" that could protect or inoculate young people from the persuasive power of advertising (Rossiter \& Robertson, 1977). Many different instructional techniques have 
been used to teach advertising analysis to help kids learn to be skeptical and resistant to advertising. Critical questions are a common strategy to practice student's advertising analysis and critical thinking ability. Teachers put emphasis on the skills of analyzing and evaluating ads to identify the message purpose, target audience, point of view, and persuasive techniques used in advertising analysis in the classroom (Buckingham, 2003).

Most fundamentally, learning to read advertising critically supports a heightened awareness of the role of the reader in the message interpretation process. Reading a text whether it be verbal, visual, auditory or interactive -- depends upon our ability to make the symbols "mean something" through mobilizing a set of cultural codes (Barthes, 1983; Barthes, 1975). In any text, complex cultural codes overlap with each other to create unpredictable possible meanings (Smith \& Riley, 2009), requiring an active stance on the part of the reader. As we document in this paper, ESL teachers are beginning to explore the approaches to analyze print, radio, web and television advertisements with the purpose of developing students' analysis, critical thinking and literacy skills in ways that support English language learning. Classroom practice of such critical thinking skills in English is necessary for new immigrants to facilitate transition to L2 academic learning environments and settings. Rote language practice, common in beginning ESOL, may allow critical faculties to atrophy. Because the articulation of critical thinking requires sophisticated concepts, vocabulary and syntax, practice is often omitted until ELLs reach intermediate or advanced stages of language acquisition. We believe that with effective language supports and the use of visual media, ELLs can practice the sorts of critical thinking they will need to analyze texts while in the beginning stages of English acquisition.

\section{Method}


This case study profiles the teaching strategies one teacher used to support the articulation of critical thinking about visual ads for media literacy development and English acquisition. In collaborating on this research project, the first author designed and supervised the research project, developed the literature review, and coordinated the data collection, analysis and manuscript preparation. The second author served as research assistant for the study, observing every class and preparing detailed field notes of each session, noting examples of instructional practices, informational content, media examples, interaction style and other skills used to engage students. She composed interview questions and met with the participating teacher to discuss the data at regular intervals throughout the data collection process. This approach allowed the second author to verify the observational data on instructional approaches with the participating teacher's perspective and gain insight into the teacher's intentions as well as nuances of the instructional design. The third author served as the participating teacher in the program, creating, adapting, designing and implementing media literacy instructional practices for ESL students. The third author also reviewed portions of the manuscript to verify and revise sections about instructional design intentions. The interviews of the third author by the second author during the implementation of the ad analysis unit may have informed the participating teacher's reflective practice. However, the third author did not participate in the research design or report until after the completion of the unit. Likewise, the second author did not contribute ideas for instructional design or teaching methods in interviews, but rather asked questions to verify observations and discover the teacher's intentions. Therefore, although the participating teacher is included as a third author of the report, this study is not action research. The research methods follow a case study approach with observational field notes and interview data collected 
and analyzed by outside researchers, and later reviewed by the participating teacher to triangulate the outside researchers' findings with the third author's perspective as participating teacher.

\section{Context}

The present study was conceptualized when the third author, an experienced high school English teacher, took a position teaching ESL students at a public high school in a large urban city in the Mid-Atlantic region of the United States. The school is known for placing its focus on the visual and performing arts, as well as encouraging creativity and developing media literacy and critical thinking skills. According to the school's mission statement, the arts provide an unequaled opportunity to foster intellectual growth by connecting arts and literacy. School leaders in this high school claim that visual and media literacy skills permeate through all subjects.

The school hosts a Newcomer Academy, which provides students new to the United States and to the English Language an accelerated course of study (six months to one year) to enhance their success when they transition into an ESOL program at their neighborhood school. The program is designed to provide academic and social opportunities to improve English language skills in a nurturing environment. Explicit goals include developing literacy and academic skills, augmenting social and communication skills, decreasing failure and dropout rates, and reducing the number of referrals for placement in special education programs. The program also aims to help students develop a positive self-image and integrate students into the social climate of the public schools.

\section{Sample}

Students were between 14 - 20 years old, had lived in the United States for less than one year, and scored below 2 on the W-APT (the World-Class Instructional Design and Assessment, 
or WIDA Aptitude Test for speaking, listening, reading and writing, commonly used to place ELLs in classes in the United States; in the state where the research was conducted, a score below 2 indicates "Non-English Proficient"). Most newcomer academy students were below grade level on their primary language assessment and all had limited or interrupted formal schooling. Fourteen students participated in the study including five girls and nine boys from countries including China, Cambodia, Vietnam, Haiti, the Dominican Republic, Puerto Rico, Georgia, Philippines, Colombia, and Taiwan. For instructional purposes, students were divided into two groups, Tiger and Shark groups, according to their English level. In general, the Tiger group had a higher English level than the Shark group; however, the level of understanding and communicating in English varied in the classroom with various levels of speaking, listening, reading and writing among students in each group.

The program consisted of a 12-lesson unit on media literacy (ML) with a focus on print advertising, taught over a period of four weeks. The participating teacher used a range of media and technology, including a data projector to display ads, photocopies of print ads, magazines from the library, and a class website where students could view ads and write about them on their own wiki pages. At the beginning of each class, the participating teacher arranged for the students to sit in a half circle with computers on their desks. He also wrote down a list of specific activities for the period on the blackboard. During the class, students were encouraged to express any ideas that came to their mind. The teacher commonly used follow up prompts including "why" and "how" questions. The participating teacher repeated instructions as needed and wrote important information and vocabulary on the blackboard.

Media Literacy (ML) Instructional Practices for Analyzing Advertising with ELL Students 
We examine four instructional practices used by the participating teacher, which all focus on strategies involving the use of critical questions to analyze advertising: (1) the cloze technique; (2) the question generation (“Jeopardy!") approach, (3) practice in analyzing ads using critical questions, and (4) a collaborative writing activity resulting in the creation of a multi-paragraph multimedia document. For all activities, print ads were displayed one at a time on a data projector, followed by active discussion of the critical questions, as shown in Table 1 . In introducing the activity, the participating teacher asked students for first reactions to the adsinitial, automatic thoughts, saying, "What do you think when you see this? How do you feel?" After each response, the teacher asked, "What made you think or feel that?" This pattern of questioning led many students to point to evidentiary support from the media text. In many cases, students would explain their thinking about cultural meanings using their prior knowledge.

Table 1 goes here

When the critical questions were first handed out to students, some could not fully understand them. Explaining the questions in detail was required to help students become acquainted with all the questions and feel comfortable in answering them. At the beginning, most students depended on the participating teacher to ask them questions about ads and scaffold the learning experience. For example, when talking about an ad that featured a person thrusting his shoulders forward in a defensive and aggressive way, the participating teacher said, "The posture communicates a message. Can you describe what the message is?" Then, he would connect 
student observations, comments and thoughts or ask students to connect those thoughts to key media literacy concepts and progress to ask ML questions and get students to expand their answers. By making connections to each others' ideas and to the ML questions and concepts, students gradually came to be able to participate in a shared group analysis of media texts.

\section{Selecting Ads for Use in the Classroom}

Before turning to a more careful description and analysis of the instructional practices, we must describe the approach used by the participating teacher in selecting print ads for analysis. A wide variety of commercial print ads were selected from magazines and newspapers. Most of the ads were closely related to products used in daily life, such as food, candy, drinks, hand wash and camera, which stimulated students' desire to share their ideas more freely about something they actually come across every day and for which they had already acquired some English vocabulary and sense of cultural value in the U.S.

The participating teacher used Internet searches to find interesting ads, looking at advertising industry blogs and advertising websites like Advertising Age. He also sometimes searched Google using key terms about themes of interest, like ethnicity, gender, and targeting kids. Students showed great interest in most of the ads chosen by the participating teacher. One student was asked whether he liked the ads the participating teacher had chosen for them. He explained that the ads were visual and very interesting. Judging from students' responses, reactions and behavior, the students found the ads to be useful, funny and interesting. A sample of ads selected by the participating teacher is shown in Figure 1.

Figure 1 goes here 
In deciding on which ads to use in the class, the participating teacher looked for ads that communicate clear visual messages in a powerful way. He was particularly interested in selecting ads with both explicit and implicit messages. He also used ads for familiar products, which gave students an opportunity to apply prior knowledge in analyzing the message. The participating teacher also had elaborate criteria for avoiding particular types of print advertising. For example, he avoided the use of ads with a lot of text, except as a challenge for more advanced students. He was also attentive to avoid obscure or very specific popular culture references in the ads' visuals or messages, which new immigrant students might not understand. He avoided the use of very explicit sexual imagery because, according to the participating teacher, "the cultural differences among students require a long conversation about sexuality in different cultures and families, which cuts into time we need to practice core concepts. It's a worthwhile discussion for another time." He also avoided alcohol and cigarette ads before discussing related health issues with new immigrant students finding that those ads could too easily become a vehicle for demonizing the business of advertising instead of understanding communication strategies in ads that could be extended to analyzing other texts.

\section{Using the Cloze Technique to Support Vocabulary and Comprehension Skills}

TESOL teachers have used the cloze technique since the late 1950s when it was first recognized as a useful device for testing the language skills of native and non-native speakers. As a teaching device, the learner is presented with a reading passage with certain key vocabulary words omitted. The student must generate the missing word by making inferences about meaning from the other words in the passage. As Oiler and Conrad (1971, p.187) explain, this instructional technique requires that the student "perform a task which is not unlike what native speakers do in sending and receiving messages." Listeners anticipate what the speaker will say 
next to either overtly or covertly supply missing words and phrases; similarly, writers search for the correct word as they compose.

The participating teacher used the cloze technique to support listening, reading and vocabulary development. First, on individual laptop computers, students listened to an audio recording of the teacher reading a short passage analyzing a print ad while they read along with a transcript of the passage, which omitted several key words. As they listened, students had to choose the correct word to fill in the blanks in the written transcript from a group of words provided. To fill the correct word into the incomplete sentence, students had to use the meaning and the pronunciation of every word and sentence, which promoted their vocabulary as they used online dictionaries and translations to complete the exercise. Table 2 shows an example of an activity, designed by the participating teacher, using the cloze procedure as a scaffolding mechanism to support advertising analysis.

Table 2 goes here

This exercise was crafted by the teacher to be within the students' zones of proximal development: it challenged them with new vocabulary, but did not overwhelm them; it challenged them to understand meanings and match questions with paragraphs, but allowed a degree of problem solving through word matching for them to fall back on if more holistic meanings and concepts proved too difficult. The use of an audio recording allowed students to go at different paces, and the technology allowed for as many repeated readings and listening moments as each student required. Students were able to work independently at the computer, and strategic seating arrangements enabled the more technology-savvy students to informally 
assist less-experienced students. Most importantly, for students who are unfamiliar with the specific cultural practice of critical analysis, the cloze procedure engaged students in close examination of a specific model, helping students to recognize the characteristics of a non-trivial examination of advertising that moves from careful description to sustained analysis.

\section{Generating Questions}

The practice of generating a question that is answered by a specific text is the skill that is tested on popular television program, "Jeopardy!" where contestants are given a short passage and asked to generate a question that can be answered by that text. Computational linguists have studied this problem in relation to machine translation, finding that question generation involves significant use of context clues (Heilman \& Smith, 2009). Table 3 shows an example of the worksheet used with this activity. Students were asked to read the answers, which are sections of an analysis of the ad, and then they were asked, "Which question matches each answer?"

Students became so active and engaged in these exercises that they remembered most of the key critical questions for subsequent discussions and for a pop quiz at the end of the unit, which the teacher used to gauge students' retention of the key ML questions that he wanted students to employ as tools in the analysis of media texts in subsequent units.

Table 3 goes here

\section{Practicing Analysis Using Critical Questions}

Some approaches to implementing media literacy education with adolescents emphasize the use of critical questions (Scheibe \& Rogow, 2011). After analyzing several ads with answers provided, students were required to generate their own answers. Because students had begun 
with the cloze activity and the Jeopardy! question generation activities where model answers were available to them, students had the ability to express critical thought more easily. To improve speaking skills, students were encouraged to express their ideas from any perspective by sharing their ideas about ads at the front of the room using the big screen of the classroom smartboard to point out visual details. The participating teacher showed evident pleasure at being in the middle of students as they built meanings from texts and from each others' readings of texts. He explained, "Between the students' efforts at understanding each other, my involvement in repeating their ideas in simple English to the class, and our efforts to apply new media literacy concepts, the whole class discussion was very exciting to participate in.” By scaffolding students' analysis ability step by step and pushing them to climb to another higher level, the participating teacher was engaging in the graduate release of responsibility model (Pearson \& Gallagher, 1983), where students eventually were able to demonstrate their ability to analyze ads logically and coherently in paragraph form.

\section{Using Online Wiki Writing for Partners to Select and Analyze Ads}

Students were divided into several groups and asked to choose an ad from a website which was provided by the participating teacher. Students were also asked to choose and bring their own ad from a magazine of their choice for individual analyses. They were required to analyze the ad using the questions provided on Table 1 and to write in full paragraphs. The following day, the participating teacher checked students' homework papers and highlighted their grammatical errors, so students' grammar skills could improve through the writing process (grammar and pronunciation support connected with formal learning from other class periods focused on these areas of instruction). Students were then required to discuss and type up a group analysis to post online. By working with partners, students strengthened small group discussion 
skills. Group presentations created an opportunity for students to practice speaking English in public. The participating teacher printed students' answers out, wrote comments and grammatical corrections, and then returned them to students for further revision. In the class, the students then presented their ad analysis with other students. The participating teacher corrected students' pronunciation and guided them to add more ideas to the analysis. The participating teacher made strategic use of grouping to support students' cooperative learning, and allow for meaningful translations of words and concepts from home languages (L1) to English (L2) and back again between students with common L1. Students also showed genuine interest in understanding each other's ideas and making sure all students in their groups could share part of the presentation in an understandable way. The use of these four instructional methods offered students explicit, repeated practice using critical analysis skills with a variety of engaging, highly visual texts, which engaged and sustained student interest throughout the 12-lesson unit of instruction. Figure 3 shows a sample of student online writing.

Figure 2 goes here

The participating teacher was surprised that the introductory analysis skills were easier to teach than he had expected. He explained, "The fact that kids were spontaneously applying the analysis concepts and inquiry techniques to other texts (like watching movies for health discussions) encouraged me to support and draw out such transfers." As students gradually recognize how the critical questions help them discuss other texts, the meaningfulness of the ad analysis practice seemed to become more apparent to them. Of course, it is not usually difficult to convince new language students of the importance of any given activity; they are in such a vulnerable position 
with so little communication and cultural competency that they tend to assume that all activities are meaningful. Still, we observed an extra level of engagement as students were able to practice academic skills using the texts of their everyday experiences and connect them to their prior knowledge, as well as to spontaneously apply critical questions and analytic language to subsequent activities involving visual texts. These activities aimed to strike a balance between learning new academic and cultural language and knowledge, and connecting with students' prior knowledge, home cultures, and everyday experience.

\section{Focus on Print Media}

Each of the 12 lessons implemented by the participating teacher focused on print advertising. But the teacher's focus on this particular type of advertising created a bit of a disconnect from the way these students experience advertising in the context of their everyday experience. By focusing on print, or magazine ads, the teacher was able to exploit the rich visual communication, limited use of words, and relative simplicity of elements as a means to promote language production, reception and comprehension. However, most of the students did not experience print advertising as an everyday part of their lives. They were not regular magazine readers, so when the participating teacher encouraged them to choose their own magazine ads, they had to choose magazines from the library that they had never read regularly before. As a result, the culminating individual ad analysis writing assignments were more difficult and tedious than they would have been otherwise. Some students made overt references to TV and Internet ads that they wanted to discuss in class, but the participating teacher did not want to introduce additional English language vocabulary necessary for moving picture and online media analysis. The participating teacher deemed the trade-off worthwhile sacrificing the authentic meaningfulness of the media from students' lives for the ability to work with texts and analytic 
language within the students' zones of proximal development.

\section{Beyond Advertising Analysis}

The participating teacher used many of the strategies described in this paper in relation to learning about subjects far beyond the topic of advertising. When students studied the Thanksgiving holiday and Native American cultures, the participating teacher used film discussion techniques to build class interpretations of a clip from Terence Mallick's New World depicting a first encounter between American Indians and English settlers. Students used new adjectives of emotions to describe their interpretations of onscreen characters' feelings, and they described and acted out and pointed to details of the film's construction to answer the question "What in the film made you think or feel that?" Similarly, the participating teacher used the cloze technique for a unit about public murals, where assignments in their art class required students to create panels of a mural to represent the Newcomer Learning Academy at the school. Such reading/listening/writing/viewing assignments featured written interpretations in plain language of local murals and the stories behind them. As they did with ads in the ad analysis unit, students read along and listened to the passage, paused and reviewed the recording to fill in the blanks with new, target vocabulary, and paused to look at the picture of the mural to understand the meanings in the text. During this mural unit, students also practiced group discussion and interpretation of visual texts (the murals). Students learned to value each other's ideas and to back up ideas with textual details and elaborations of their understandings and connections to real life via their cultural understandings. In these discussions, the students used vocabulary and ideas from the writing assignments in their talk, and added to these ideas. They also used online translation tools to build their own individual written interpretations of murals. Students also gave individual presentations to the class of their interpretations of a mural of their 
choice from a public mural website; so, they practiced speaking their written pieces from memory and notes. Throughout these writing and speaking assignments, students had time for independent work while the participating teacher circulated and conferenced about feedback the participating teacher had given them on earlier drafts. The program gave mid-to-advanced beginner ELLs authentic encounters with content-driven academic units to practice English through exercising media literacy skills. The lessons offered an opportunity for embedded, inquiry-based academic and everyday English practice, which balanced direct language, culture, and academic skill instruction and practice in their other daily English classes. The mural unit helped students extended their use of media literacy concepts for critical thinking to ideas about social justice and community action, which they put into practice in their art classes. Through collaboration with the art teacher, the students designed and created their own panels for a mosaic mural representing their newcomer program, which they proposed in writing (using concepts of message, purpose, audience and representation), and presented to mainstream art students upon completion.

\section{Discussion}

To build the critical analysis skills of new immigrants, well-structured activities and assignments can make an important difference. When the number of linguistic and cultural challenges in initial assignments is limited, students practice to internalize skills and they feel a sense of accomplishment when subsequent assignments are progressively more complex and open-ended. Given careful supports in discussion and assignments, new immigrant students with a wide range of cultural backgrounds, academic experiences, and abilities could participate in media literacy inquiry and skill practice through ad analysis. They spontaneously applied the skills learned in the classroom to a wide range of other classroom and informal learning 
activities. As the participating teacher noted, "I was encouraged to see students transfer these inquiry approaches and media literacy concepts to other discussions and to their writing in journals."

One of the reasons that we are enthusiastic about the use of media literacy instruction in the context of ESL is that we believe in supporting students' identity development while offering them new opportunities in using language and knowledge. It enables them to acquire the skills and knowledge for participation in new discourse communities, especially those that hold great power in contemporary society. Many scholars have noted that language teaching should give students the ability to understand and articulate preferred meanings by occupying identity positions in the culture of power, to negotiate and challenge preferred meanings of the culture of power through meaning making from home and alternative identity positions, and resist and refuse the meaning making practices that the student deems oppressive (Smith \& Riley, 2011).

Concepts that we commonly use to think about identity, like race, class and gender, are ways of thinking about groups of people, to which the media literacy concepts of audience and representation connect. By allowing students to practice inquiry in a structured way using basic media literacy concepts, students in this case study spontaneously used the lenses of race, class and gender to discuss audiences. For example, when discussing a skiing ad, many students agreed that it targeted rich people because the sport requires a lot of money. Students also connected the ethnicity of actors and models in ads with target audience and message in different ways--sometimes students simplistically matched the race of a model with the race of the target audience, but other times, as when students in this study looked at a black and white ad for a camera that depicted a white female model who looked like a classic Hollywood movie star, they did not see any particular ethnic correspondence between model and audience (in that case, they 
interpreted the choice of model using the concepts of fame and preserving memory). We think it is important to support students' recognition of such concepts of race, class, and gender, which can be useful and are culturally common for responding to media literacy questions. However, it is just as important to encourage students to use a range of conceptual understandings and even to question these concepts themselves. ELL students are most often, by identity, "contingent to" or outside mainstream American cultural points of view. In practicing media literacy through ad analysis, the complex job of the TESOL teacher is to help students find the vocabulary to understand and articulate both their own points of view and the American cultural points of view on messages that they see in ads. By analyzing and producing media from different points of view for different purposes, students get to inhabit and imagine different ways that people see and represent reality from different cultural points of view. Through this process, students can develop their own ways to judge the value of seeing and understanding representations using different cultural points of view and different concepts.

We must emphasize, however, that we think it is very important for students to have practice with inquiry using the key questions from their own points of view (which may or may not notice or emphasize differences using particular concepts such as race, gender, and class), before being pushed to use particular concepts or others' points of view. Once students have some practice and confidence adapting basic media literacy inquiry in their own words with their own sense of identity, then teachers can push students to try different approaches from particular political points of view to promote social justice or media reform or health agendas (or whatever purpose) without abusing their own power over the students. We agree to a certain extent with critical scholars (e.g., Kellner \& Share, 2007) that without teachers or experts modeling (and requiring practice of) certain politicized conceptual approaches to media analysis and production 
(such as feminist or Marxist readings), students' work may be more likely to reproduce the status quo, which often involves many unjust and unfair realities. And, although we do not believe that basic media literacy inquiry alone will lead students to spontaneously produce analysis and production practices that will efficiently nor effectively address social justice or political economy issues, we do think it is important to allow students to practice media literacy inquiry on their own terms as much as possible, especially in the beginning, to allow them the best chance at critical autonomy (choosing meanings, identity positions, and paths of thought and action for themselves), rather than simply replacing their own points of view with the teacher's.

Media literacy questions disturb the uncritical reception and reproduction of cultural meanings in media texts enough to begin the process toward critical action without directing the kinds of meanings that learners produce using the key questions and concepts in reflective practice. It was obvious to us, that in the context of working in K-12 public education with new immigrant students, there is a balancing act between trying to honor who students are and what they know, what they want to know and what educators at school and in the community think they should know. In the classroom, this usually involves trying to design constructivist and inquiry approaches to knowledge production, to include everyday texts and texts from students' home cultures, and to balance these student centered approaches with efficient direct teaching of language, skills and cultural knowledge needed to participate in the student-centered approaches and other school and community events. All this lofty talk comes crashing down to the everyday struggle with ESL learners to provide meaningful opportunities to practice speaking, listening, reading and writing in English and to efficiently teach and learn vital cultural and academic knowledge that will allow them to access more social situations for more opportunity for participation in American culture as quickly as possible. The day-to-day struggle is in choosing 
what to spend the time on that will be most helpful for improving English communication and cultural participation. In this study, for example, the participating teacher knew that media production is important for learning and practicing media analysis and media literate habits of mind. However, the goal was not to train students specifically in ad analysis, per se; he was primarily using ad analysis as a way of introducing students to media literacy questions and approaches to analyzing any texts using those key concepts and questions. Therefore, the participating teacher chose not to spend time with students creating ads, which he saw as a much more difficult and time-consuming task for new English speakers than his intro to ad analysis. Instead, after the ad analysis unit, the participating teacher had students create media from their own experiences, which he thought they would find more meaningful, using the media literacy concepts: e.g., they made digital comics from pictures of their field trip to Washington D.C. using media literacy questions to create and discuss their work. This way, students also practiced a near transfer of their new skills between media forms.

There is no denying that all these methods and instructional strategies that we describe in this manuscript were helpful for students in practicing critical thinking, developing media literacy and acquiring English. However, the project also faced some challenges. One month is too short for students to practice and master the skill of advertising analysis, especially for the new immigrant students who have difficulty with the English language. In developing their written work, students were allowed to use Google Translate to find words to express and write their ideas. Although the students were able to increase their understanding of English grammar and add more words to their ever-growing vocabulary, using the tool sometimes slowed down and confused students. There is also the question of whether the students are able to remember the words they need to answer ad-related questions. In this case, the participating teacher's 
methods of having students review terms through in-class exercises and at home studying were critical to the students' ability to retain new information.

Not every print ad is suitable to be analyzed. When choosing an ad, the message, values and suitability for the students' level of comprehension need to be considered. Choice of material and exercise design must be relevant to the ads as well. It is suggested that each teacher prepares analyses of at least two ads to share and discuss as models and language resources for students' work with subsequent ads, which saves time and energy. For future teachers wanting to teach ad analysis to non-English speaking students in the ELL classroom, it would be most helpful for them to be trained by media literate advocates and specialists prior to their teaching. The participating teacher described in this study was an advanced doctoral student in mass media and communication with familiarity with the scholarly and professional literature on mass media, secondary education and TESOL as well as significant expertise as a public high school teacher. Because many schools restrict access to digital media infrastructure, this may also be an obstacle for some teachers and students. This study has shown how a mix of low-tech and high-tech activities support student learning. While computer resources were used to great effect by the participating teacher and class, most activities could be adapted for less sophisticated technology with pen, paper, posters, magazines, tape recorders and a blackboard.

Advertising analysis is a useful way to practice students' critical thinking and English language skills. This study illustrated that print ad analysis can be an effective way to motivate new immigrants in ESL classroom by developing their critical thinking and foreign language skills based on instructional activities. We believe that instructors should consider using advertising analysis method to help students meet the goal of improving critical thinking and language skill in a way that is motivating and interesting to students. 


\section{Author Bio}

Renee Hobbs is Professor and Founding Director of the Harrington School of Communication and Media at the University of Rhode Island. She is an internationally-recognized expert in digital and media literacy education and has authored five books and more than 100 scholarly articles and publications.

Haixia He teaches English at Ningxia University in Western China and specializes in the design of media- and film-based language activities and curriculum to advance second language learning.

Michael RobbGrieco is a former high school English and ESL teacher and a doctoral candidate at Temple University's School of Media and Communication. His work examines the intellectual history of media literacy education and the use of humor as a pedagogical strategy to promote critical analysis of media in the language arts classroom. 


\section{References}

Aufderheide, P. (1993). Media Literacy. A Report of the National Leadership Conference on Media Literacy. Washington DC: Aspen Institute.

Barthes, R. (1983). Empire of signs. New York: Hill and Wang.

Barthes, R. (1975). S/Z. New York: Macmillan.

Bremer, E. (2011). Unit Plan for Introduction to Media and Advertising Cultivating Critical Thinking Skills. Retrieved from http://teachingfilmandmedia.wikispaces.com/Unit+Plan+for+Introduction+to+Media+an $\underline{\mathrm{d}+\text { Advertising+Cultivating+Critical+Thinking+Skills. }}$.

Brucks, M. Goldberg, M., \& Armstrong, G. (1986). Children's cognitive responses to advertiisng. In R. Lutz (Ed.), Advances in consumer research Volume 13. Provo, UT : Association for Consumer Research, pp. 650-654.

Buckingham, D. (2003). Media education. London: Polity.

Cross, J. (2011). Comprehending news videotexts: The influence of the visual content. Language Learning \& Technology, 15(2), 44-68.

Dewey, J. (1933). How we think. Chicago: Henry Regnery.

Freire, P. (1973). Education for critical consciousness. New York: Herder and Herder.

Habermas, J. (1998). On the pragmatics of communication. Cambridge, MA: MIT Press.

Hayakawa, S. I. (1939). General semantics and propaganda. Public Opinion Quarterly 3, 197 208.

Heilman, M. \& Smith, N. (2009). Question generation via overgenerating transformations and ranking. Technical Report CMU-LTI-09-013, Language Technologies Institute, Carnegie 
Mellon University.

Hobbs, R. (2010). Digital and Media Literacy: A Plan of Action. Washington, D.C: The Aspen Institute.

Hobbs, R. (2007). Reading the media: Media literacy in high School English. New York: Teachers College Press.

Hobbs, R. (2004). Analyzing advertising in the English language arts classroom: A quasi experimental study. Studies in Media \& Information Literacy Education, 4(2), 1-14. http://dx.doi.org/10.3138/sim.4.2.002

Hobbs, R. \& Jensen, A. P. (2009). The past, present and future of media literacy education. Journal of Media Literacy Education 1(1), 1 - 11.

Johnson, K. E. (2006). The sociocultural turn and its challenges for second language teacher education. TESOL Quarterly 40(1), 235 - 257. http://dx.doi.org/10.2307/40264518

Kellner, D. \& Share, J. (2007). Critical media literacy is not an option. Learning Inquiry 1, 59 69. http://dx.doi.org/10.1007/s11519-007-0004-2

Korzybski, A. (1994, 1933). Science and sanity: An introduction to non-Aristotelian systems and general semantics. Ft Worth: Institute on General Semantics.

Livingstone, S., \& Helsper, E. (2004). Advertising foods to children: Understanding promotion in the context of children's daily lives. A review of the literature prepared for the Research Department of the Office of Communications (OFCOM). Media@LSE, London, UK.

National Association for Media Literacy Education (NAMLE). Core Principles. Retrieved March 24, 2012 from http://namle.net/publications/core-principles/ 
Oiler, J. \& Conrad, C. (1971). The cloze technique and ESL proficiency. Language Learning

21(2), 183 - 195. http://dx.doi.org/10.1111/j.1467-1770.1971.tb00057.x

Park, Y. (2011). Using news articles to build a critical literacy classroom in an EFL setting. TESOL Journal 2(1), 24 - 51. doi: 10.5054/tj.2011.24413

Pearson, P. \& Gallagher, M. (1983). The instruction of reading comprehension. Contemporary

Educational Psychology 8, 317 - 344. http://dx.doi.org/10.1016/0361-476X(83)90019-X

Pennycook, A. (1999). Introduction: Critical approaches to TESOL. TESOL Quarterly 33(3), 329

- 348. http://dx.doi.org/10.2307/3587668

Quinlisk, C. C. (2003). Media literacy in the ESL/EFL classroom: Reading images and cultural stories. TESOL Journal 12(3), 35-40.

Rossiter, J.R. \& Robertson, T. (1974). Children's TV commercials: Testing the defenses. Journal of Communication, 24 (3), 137-144. http://dx.doi.org/10.1111/j.1460-2466.1974.tb00418.x

Scheibe, C. \& Rogow, F. (2011). A teacher's guide to media literacy. Thousand Oaks: Corwin/Sage.

Vygotsky, L. S. (1978). Mind in society. Cambridge, MA: Harvard University Press.

Wertsch, J. V. (1985). Vygotsky and the social formation of mind. Cambridge, MA: Harvard University Press.

Vize, A. (2011). Engaging ESL students in media literacy. Science Education, 61, 78-81.

Young, B. (1990). Television advertising and children. London: Clarendon Press. 
Table 1. Key Questions for Analyzing Media Messages

\begin{tabular}{|c|c|c|}
\hline \multirow[b]{2}{*}{$\begin{array}{l}\text { AUDIENCE \& } \\
\text { AUTHORS }\end{array}$} & $\underline{\text { AUTHORS }}$ & A1. Who made the media text? \\
\hline & PURPOSE & $\begin{array}{l}\text { A2. What is the purpose? Why was this made? } \\
\text { A3. Who is the target audience? }\end{array}$ \\
\hline \multirow{3}{*}{$\begin{array}{l}\text { MESSAGES \& } \\
\text { MEANINGS }\end{array}$} & Content & $\begin{array}{l}\text { M1. What is this about? What is the main idea? } \\
\text { What are the messages? }\end{array}$ \\
\hline & TECHNIQUES & $\begin{array}{l}\text { M2. What techniques are used to attract attention? } \\
\text { What techniques communicate the message(s)? }\end{array}$ \\
\hline & $\begin{array}{l}\text { INTER- } \\
\text { PRETATIONS }\end{array}$ & $\begin{array}{l}\text { M3. How can different people understand the } \\
\text { message(s) differently? } \\
\text { M4. What is left out of the message(s)? }\end{array}$ \\
\hline \multirow{3}{*}{$\begin{array}{l}\text { REPRESENTA } \\
\text { TIONS \& } \\
\text { REALITY }\end{array}$} & CONTEXT & R1. When, where and how was this shared? \\
\hline & $\begin{array}{l}\text { REPRESENT- } \\
\text { ATIONS }\end{array}$ & $\begin{array}{l}\text { R2. What lifestyles, values, and points of view are } \\
\text { represented? }\end{array}$ \\
\hline & CREDibility & $\begin{array}{l}\text { R3. Is this fact, opinion, or something else? } \\
\text { R4. How does the message relate to reality? } \\
\text { Are the messages true and correct? }\end{array}$ \\
\hline
\end{tabular}

Source: Project Look Sharp 
Table 2

Sample Cloze Analysis

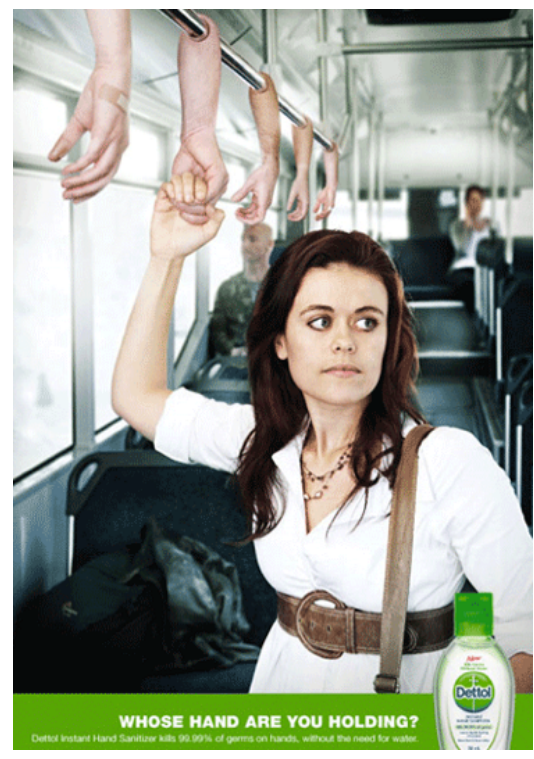

\section{Words for the blanks}

Magazine audience context collaborated

$$
\text { purpose targets message attention }
$$

technique company differently idea represents

leaves point of view agency product

facts persuade lifestyle

1. The Dettol made this ad for a hand sanitizer. The authors are the company and the ad that they paid. They to create the ad.

2. The ad was in People on a full page next to an article about a movie star in April 2011. Readers saw the ad in this

3. The target is people who ride the bus. Mostly working class people ride the bus. This ad also shows a woman, so maybe it women more than men.

4. The most important in the ad is that buses are not clean. When you hold a handle in the bus, you can get the germs of other people on the bus. The main is that you must clean your hands after you use the bus.

5. The of the ad is to people that they need to buy Dettol hand sanitizer. It tries to scare you a little. 
Table 3

Question Generation Activity

Instructions. Study the ad and then write the question that fits the answer.

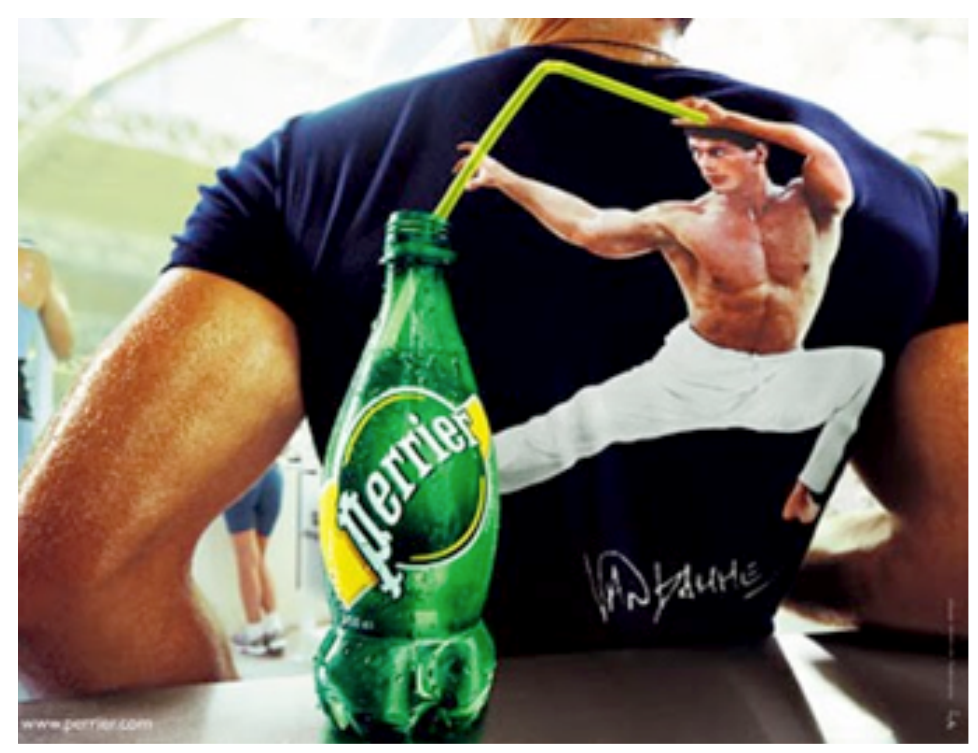

Question:

Answer: The company that owns Perrier made this ad for water.

Question:

Answer: This ad was in a Sports Illustrated magazine in April 2011. It was on a full page next to a story about a basketball player.

Question:

Answer: They made this ad because they want people to buy the water. They want to persuade the reader to feel that Perrier water is strong, exciting and healthy.

Question:

Answer: There are a few messages in this ad. Perrier is a healthy drink for strong people. Perrier is exciting, like a kung fu fighter movie star. Perrier is part of attraction between men and women.

Question:

Answer: The main idea is that Perrier is an exciting drink for strong people.

Question:

Answer: The target audience is men and boys who like action movies and want a strong body. Another target audience is women and gay men who like to look at strong men's bodies. This ad was made for middle class and wealthy people. These people can afford to buy a gym membership.

Question:

Answer: The ad uses perspective to attract attention. There is a kung fu fighter on the man's tshirt. The fighter has no shirt and many muscles. He looks like he is holding the straw in the bottle. The straw is like his weapon for kung fu. It's interesting. 
Figure 1

Ads Selected for Analysis by the Participating Teacher
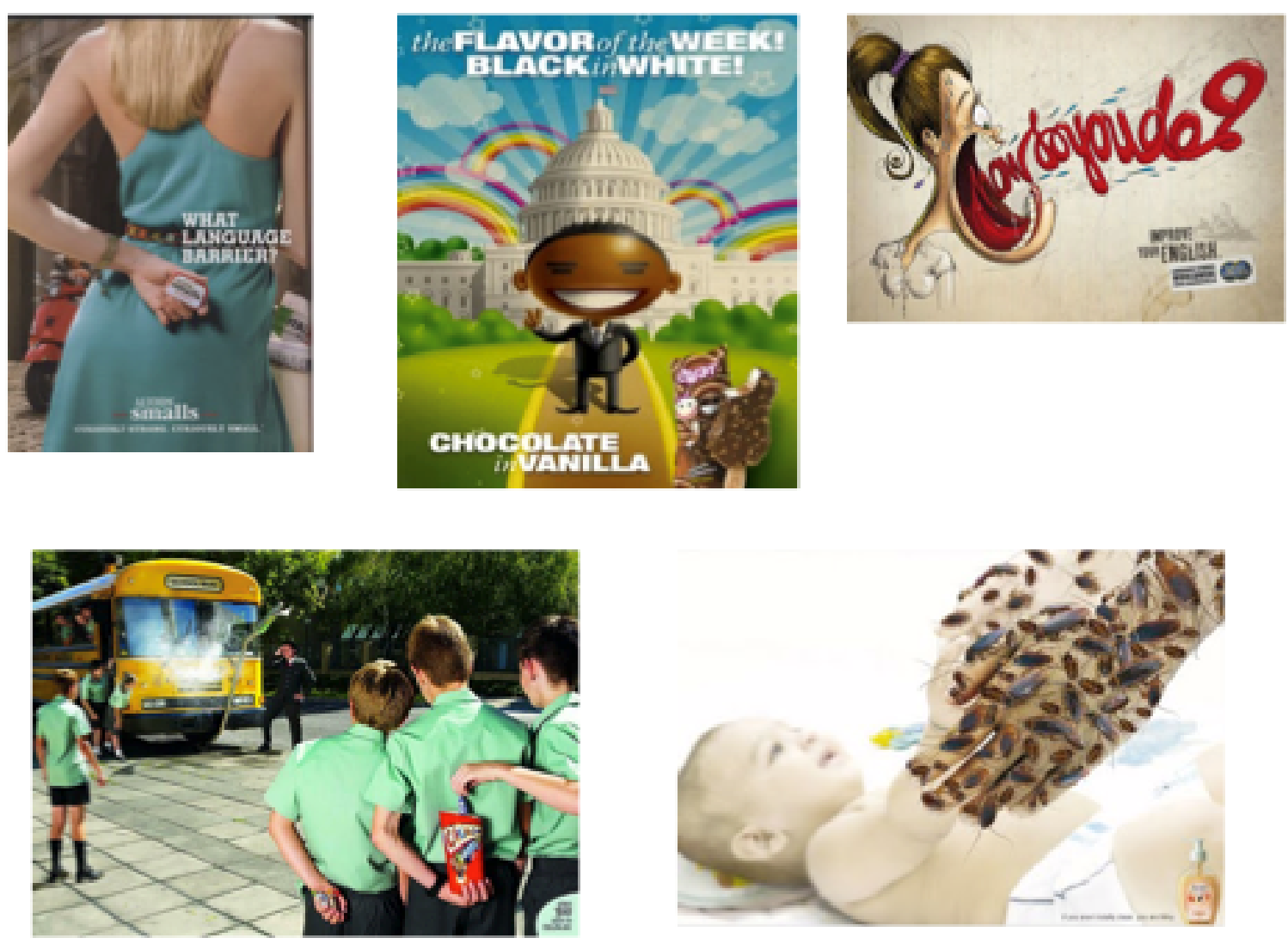
Figure 2

Student Writing Sample: Advertising Analysis

\section{NLA Tigersharks}

\begin{tabular}{l}
$\begin{array}{l}\text { Home } \\
\text { Justin's Ad } \\
\text { Analysis }\end{array}$ \\
\hline Ad Analysis G1 \\
\hline Ad Analysis G2 \\
\hline Ad Analysis G3 \\
\hline Ad Analysis G4 \\
\hline Ana's Ad Analysis \\
\hline Hai's Ad Analysis \\
\hline Joseph's Ad \\
Analysis \\
\hline Lawrence's Ad \\
Analysis \\
\hline Maria's Ad \\
Analysis \\
\hline Nan's Ad Analysis \\
\hline Nia's Ad Analysis \\
\hline Van's Ad Analysis \\
\hline Vichet's Ad \\
Analysis \\
\hline Vladimy's Ad \\
Analysis \\
\hline Sitemap \\
\hline
\end{tabular}

\section{Nan's Ad Analysis}

I am Nan. and I chose this ad to analyze. This is what I think of it...

Authors and Audiences

The Geico insurance company made this ad. They persuade driver to pay money for this insurance. The target audience of the ad is driver.

\section{Messages and Meanings}

The picture communicate all the kind of car to use a rope to bind together.The main idea is the company can help you save "a bundle" (a bundle means all the kind of car can pay the money for all car for insurance, we have common insurance that only for one car, not have for all the car ). They use the words on the top to attract attention. The pictures and words use techniques to communicate the message. They help you save on more than just car insurance of insurance policy are they selling.

\section{Representations and Reality}

The students everyday take the bus, so they don't need this message. The company help us to save how much money down.we could enjoy a Multi-Policy discount when you insure more than one type of vehicle.
Insure all your vehicles with GEICO. You could save a bundle.

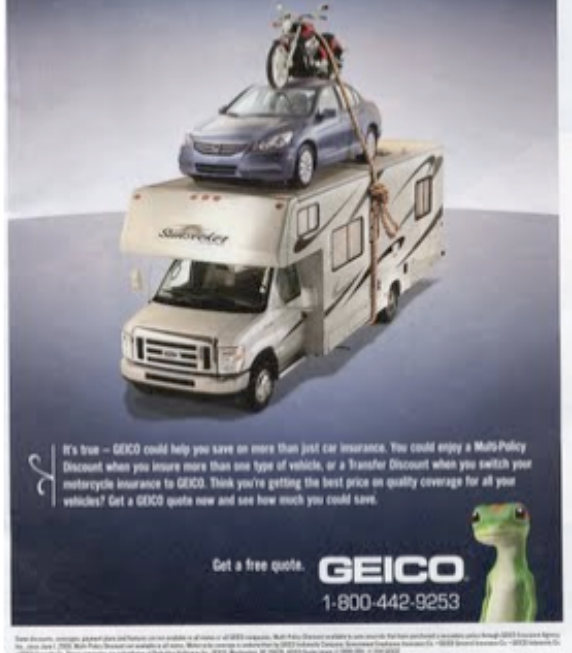

